\title{
Elevated plasma level of soluble triggering receptor expressed on myeloid cells-1 is associated with inflammation activity and is a potential biomarker of thrombosis in primary antiphospholipid syndrome
}

\author{
Yonatan Edel ${ }^{1,3}$, Vitaly Kliminski ${ }^{2,3}$, Elisheva Pokroy-Shapira ${ }^{1,3}$, Shirly Oren', Ariela Dortort Lazar ${ }^{1,3}$,
} Yael Pri-Paz Basson ${ }^{1}$, Mohammad Egbaria ${ }^{1}$ and Yair Molad ${ }^{1,2,3^{*}}$ (D)

\begin{abstract}
Background: Soluble triggering receptor expressed on myeloid cells-1 (sTREM-1) is an innate-immune receptor found in blood. Its presence reflects innate immune cell activation. We sought to investigate plasma sTREM-1 levels in patients with primary antiphospholipid syndrome (PAPS).

Methods: A cross-sectional, case-control design was used. Plasma sTREM-1 levels were analyzed by enzyme-linked immunosorbent assay (ELISA) in consecutive patients diagnosed with PAPS or asymptomatic antiphospholipid antibody (APLA) carriers and controls.

Results: The study cohort included 33 patients with PAPS, 10 asymptomatic APLA carriers, and 73 controls. Mean plasma sTREM-1 levels were significantly higher in patients with PAPS $(299.2 \pm 146.7 \mathrm{pg} / \mathrm{ml})$ and thrombotic PAPSever (current and past thrombotic event) $(327.2 \pm 151.3 \mathrm{pg} / \mathrm{ml})$ compared with controls $(230.2 \pm 85.5 \mathrm{pg} / \mathrm{ml} ; p=0$. 006 and $p=0.003$, respectively), patients with thrombotic PAPS compared with patients with past obstetric APS $(195.12 \pm 58.52 \mathrm{pg} / \mathrm{ml}, p=0.01)$ and APLA carriers $(215.8 \pm 51.6 \mathrm{pg} / \mathrm{ml}, p=0.02)$, patients with current thrombotic PAPS $(429.5 \pm 227.5 \mathrm{pg} / \mathrm{ml})$ compared with patients with past thrombotic PAPS $(289.5 \pm 94.65 \mathrm{pg} / \mathrm{ml}, p=0.01)$, and patients with PAPS who had ever had a stroke or venous thromboembolic event compared with patients who had not ( $p=0.007$ and $p=0.02$, respectively). On receiver operator characteristic curve analysis, plasma sTREM- 1 levels differentiated patients with current thrombotic PAPS from asymptomatic APLA carriers and controls, with an area under the curve of $0.7292(p=0.0014)$ and $0.88(p<0.0001)$, respectively. Multivariate regression analysis to identify sTREM-1 predictors (thrombotic PAPS-ever, age, and sex) yielded an independent association of sTREM-1 levels with thrombotic PAPS $(p<0.0001)$.
\end{abstract}

(Continued on next page)

\footnotetext{
* Correspondence: ymolad@clalit.org.il

${ }^{1}$ Rheumatology Unit, Rabin Medical Center - Beilinson Hospital, 4941492

Petach Tikva, Israel

${ }^{2}$ Laboratory of Inflammation Research, Felsenstein Medical Research Center,

Rabin Medical Center - Beilinson Hospital, Petach Tikva, Israel

Full list of author information is available at the end of the article
}

(c) The Author(s). 2019 Open Access This article is distributed under the terms of the Creative Commons Attribution 4.0 International License (http://creativecommons.org/licenses/by/4.0/), which permits unrestricted use, distribution, and reproduction in any medium, provided you give appropriate credit to the original author(s) and the source, provide a link to the Creative Commons license, and indicate if changes were made. The Creative Commons Public Domain Dedication waiver (http://creativecommons.org/publicdomain/zero/1.0/) applies to the data made available in this article, unless otherwise stated. 
(Continued from previous page)

Conclusions: Plasma sTREM-1 levels are significantly elevated in patients with thrombotic PAPS. Levels of sTREM-1 might serve as a biomarker for thrombosis in patients with PAPS.

Keywords: Triggering receptor expressed on myeloid cells-1 (TREM-1), Thrombosis, Antiphospholipid syndrome, Biomarker

\section{Background}

Antiphospholipid syndrome (APS) is a systemic autoimmune disease characterized by thrombotic events and/ or pregnancy morbidity in the presence of persistent antiphospholipid antibodies (APLA), namely lupus anticoagulant (LAC), anticardiolipin (aCL) IgG and/or IgM antibodies, and/or anti- $\beta_{2}$ glycoprotein I ( $\left.\beta_{2} \mathrm{GPI}\right)$ IgG and/ or IgM antibodies [1]. The mechanism of clot formation is considered multifactorial and remains largely unknown. Although the prevalence of APLA in the general population ranges between $1 \%$ and $5 \%$, clinically overt thrombotic APS develops in only a minority of affected individuals, suggesting that the presence of APLA alone is not sufficient to trigger clot formation, and a "second hit" with another, perhaps inflammatory, factor is required [2].

There is increasing evidence that the pathogenesis of APS involves innate immune activation, particularly via toll-like receptors (TLRs). The TLR family of pattern recognition receptors plays a pivotal role in infectious and autoimmune diseases [3]. TLR-4 is a cell-surface receptor for bacterial lipopolysaccharide (LPS) that is mainly expressed in the cells of the innate immune system. Studies have shown that $\beta_{2}$ GPI binds to endothelial cells through TLR-4, among other receptors [3, 4], and interacts with LPS. These findings support the hypothesis that the LPS/ $\beta_{2}$ GPI complex, by activating signaling pathways in monocytes similar to the action of LPS, may account for TLR-4 involvement in the pathogenesis of thrombosis in APS [5, 6]. Several in-vivo studies using animal models of APS have shown that thrombus size was smaller in the LPS-nonresponsive mice (LPS ${ }^{-1}$ $\left.{ }^{-}\right)$than the LPS-responsive mice [7]. Additionally, a recent study of patients with primary APS (PAPS) reported an increase in the level of expression of TLR-2 and TLR-4 mRNA in peripheral blood mononuclear cells in association with evidence of endothelial dysfunction, arterial stiffening, and hypertrophy [8].

Triggering receptor expressed on myeloid cells-1 (TREM-1) is a recently identified DAP-12-associated cell-surface receptor expressed mainly on monocytes and neutrophils. It is involved in the amplification of TLR-4-mediated inflammatory responses $[9,10]$. The expression of TREM-1 is upregulated in response to LPS, and its colligation with TLR-4 results in greater production of proinflammatory cytokines and chemokines than induced by either TREM-1- or TLR-4-mediated activation alone [9-12]. At the same time, the soluble form of TREM-1 (sTREM-1) is released and apparently exerts an anti-inflammatory effect, as indicated by findings of its inverse correlation with tumor necrosis factor- $\alpha$ and interleukin-1 $\beta$ in murine sepsis [13]. Taken together, these studies suggest that TREM-1 upregulation is associated with and amplifies TLR-4-mediated monocyte/macrophage activation and that the blood STREM-1 level correlates with monocyte/macrophage membrane TREM-1 upregulation and innate immune cell activation.

In light of the growing evidence of the role of innate immunity, and TLR-4 in particular, in the pathogenesis of thrombosis in APS, we sought to investigate the plasma level of sTREM-1 in a cohort of patients with PAPS, the clinical association of sTREM-1 with thrombotic PAPS, and the possible use of sTREM-1 as a biomarker of thrombotic events in PAPS.

\section{Methods}

\section{Study population}

A cross-sectional, case-control study design was used. The cohort consisted of consecutive patients diagnosed with PAPS or asymptomatic carriers of persistently positive APLA under routine follow-up at the Rheumatology Clinic of a tertiary university-affiliated medical center. The study protocol was reviewed and approved by the local Institutional Review Board, and all participants provided written informed consent.

The diagnosis of PAPS was based on the combined presence of one positive clinical criterion and one positive laboratory criterion ( $\mathrm{aCL}$ and/or a $\beta 2 \mathrm{G} 1$ antibodies by enzyme-linked immunosorbent assay (ELISA) and/or LAC determined according to the International Society of Thrombosis and Haemostasis) on two or more occasions not less than 12 weeks apart, as stipulated in the Sydney revised Sapporo guidelines [14]. Vascular thrombosis was defined as one or more clinical episodes of arterial, venous, or small-vessel thrombosis in any tissue or organ, confirmed by objective validated criteria (unequivocal findings on appropriate imaging studies or histopathology). Pregnancy morbidity was defined as follows: one or more unexplained deaths of a morphologically normal fetus at or beyond week 10 of gestation, with normal fetal morphology documented by ultrasound or 
by direct examination of the fetus (intrauterine fetal death (IUFD)); or one or more premature births of a morphologically normal neonate before the 34th week of gestation because of eclampsia or severe preeclampsia defined according to standard definitions or because of recognized features of placental insufficiency (intrauterine growth restriction); or three or more unexplained consecutive spontaneous abortions before the 10th week of gestation, excluding maternal anatomic or hormonal abnormalities and paternal and maternal chromosomal causes. For the classification of PAPS, APLA positivity was defined as a moderate-to-high titer of aCL IgG/IgM antibody (> 40 GPL/MPL U/ml) and/or anti- $\beta_{2}$ GPI IgG/ IgM above the 99th percentile (IgG/IgM aCL/anti-$\beta_{2} \mathrm{GPI} \geq 20 \mathrm{GPL} / \mathrm{MPL} \mathrm{U} / \mathrm{ml}$ ) and/or positive LAC by either dilute Russell viper venom time test $(>1.4)$ and/or silica clotting time test $(>1.3)$. Patients with systemic autoimmune or rheumatic diseases, including but not limited to systemic lupus erythematosus, rheumatoid arthritis, and Sjögren's syndrome, were excluded from the study as were patients with evidence of infectious disease within 3 months prior to blood sampling and/or evidence of active malignancy, in addition to pregnant women, women within 12 weeks after delivery or abortion, and patients with thrombosis attributed to a non-APLA cause. Asymptomatic APLA carriers were defined as consecutive patients with persistently positive aCL IgG and/or IgM and/or anti- $\beta_{2}$ GPI IgG and/or IgM and/or positive LAC test on two consecutive occasions at least 12 weeks apart with no evidence of thrombosis and/ or obstetric features of APS and/or inflammatory or autoimmune systemic disorder, infection, malignancy and/or pregnancy or 12 weeks or less postpartum. Healthy control subjects were recruited from the hospital staff. Exclusion criteria for the control group were history of thrombosis, systemic autoimmune or inflammatory disease, current infection, current or previous malignancy, and/or pregnancy or 12 weeks or less postpartum.

\section{Clinical and laboratory data collection}

At the study encounter, participating patients were interviewed, and demographic and clinical information was systematically collected, including current age, sex, time of diagnosis, and thrombotic and/or obstetric manifestations of PAPS. Medications used at the time of the study or within the previous 3 months were recorded, specifically low-dose aspirin (75-100 mg/day), hydroxychloroquine (200-400 mg/day), warfarin (Coumadin), new oral anticoagulants, prednisone, and statins. In addition, the individual electronic charts and the hospital's computerized database were systematically reviewed for the following comorbidities: arterial hypertension, defined as systolic blood pressure higher than $140 \mathrm{mmHg}$ and diastolic pressure higher than $90 \mathrm{mmHg}$ that required antihypertensive medications; diabetes mellitus, defined as hyperglycemia requiring oral drugs and/or insulin; dyslipidemia, defined as serum total cholesterol above $200 \mathrm{mg} /$ $\mathrm{dl}$ and/or triglycerides above $150 \mathrm{mg} / \mathrm{dl}$ and/or anti-lipidemic drug use; ischemic heart disease, defined as evidence of myocardial infarction and/or evidence of coronary artery atherosclerosis obtained by either coronary catheterization or a percutaneous coronary intervention procedure; and stroke defined by evidence of neurological deficit and/or computed tomography or magnetic resonance imaging signs of brain infarct. Estimated glomerular filtration rate (eGFR) at the time of the study encounter was calculated using the Modification of Diet in Renal Disease equation [15].

Blood was collected from all patients at the study encounter and assayed in the hospital's routine clinical laboratories for complete blood count, erythrocyte sedimentation rate (ESR), and levels of serum high-sensitive C-reactive protein (hsCRP), ferritin, and creatinine.

The APLA results used for the purpose of the study were serum aCL and anti- $\beta_{2}$ GPI IgA/IgM antibodies and LAC. All factors were tested routinely at the hospital's laboratory at the most recent clinic visit prior to the study or at the study encounter. A commercial ELISA kit was used according to the manufacturer's instructions to analyze aCL IgG and IgM antibodies (Aesku Diagnostics GmbH\&Co. KG, Wendelsheim, Germany) and anti- $\beta_{2}$ GPI IgG and IgM antibodies (Inova Diagnostics, Quanta Lite, San Diego, CA, USA), and LAC was assayed according to published guidelines [16].

\section{Measurement of plasma sTREM-1 levels}

All blood samples were centrifuged at $1500 \mathrm{~g}$ for $15 \mathrm{~min}$ immediately after venous blood withdrawal and stored at $-70{ }^{\circ} \mathrm{C}$ until assayed. The plasma level of STREM- 1 was analyzed using a commercial ELISA kit (Human TREM-1 DuoSet ELISA kit, DY1278B, Bio-Techne, Minneapolis, $\mathrm{MN}$, USA) according to the manufacturer's instructions [17]. The assay plates (C19018, Corning Inc., Corning, NY, USA) were coated with the capture antibody overnight at $4^{\circ} \mathrm{C}$ and then washed with $0.05 \%$ Tween 20 in phosphate-buffered saline (PBS) (PeproTech Inc., Rocky Hill, NJ, USA) and blocked with the assay reagent diluent (5\% Tween 20 in PBS) for $2 \mathrm{~h}$ at room temperature, and then washed. Next, $100 \mu \mathrm{l}$ of serially diluted standards $(3000 \pm 23.45 \mathrm{pg} / \mathrm{ml})$, patient, and control plasma were added and incubated overnight at $4{ }^{\circ} \mathrm{C}$. On the following day, the plates were equilibrated at room temperature for $2 \mathrm{~h}$ and then washed and incubated with a detection antibody diluted with the reaction diluent containing $2 \%$ heat-inactivated normal goat serum for $2 \mathrm{~h}$ at room temperature. Next, the plates were washed, and incubated for $20 \mathrm{~min}$ at room temperature with horseradish peroxidase-conjugated streptavidin diluted with the 
reaction diluent (1:200). The plates were washed and incubated with TMB substrate (PeproTech Inc., Rocky Hill, NJ, USA) for $20 \mathrm{~min}$ and the reaction was stopped with 1 $\mathrm{N} \mathrm{HCl}$ (PeproTech Inc., Rocky Hill, NJ, USA). The absorbance was measured by a spectrophotometer (BioTek, Winooski, VT, USA) set at $450 \mathrm{~nm}$ with the correction wavelength set at $570 \mathrm{~nm}$. The results were analyzed by creating a four-parameter logistic (4-PL) curve against the optical density of the standards $(3000 \pm 23.45 \mathrm{pg} / \mathrm{ml})$ following the subtraction of the optical density of the averaged blank controls. All plasma samples and standards were assayed in duplicates. The difference between ELISA plates was monitored by including specific healthy control plasma samples in each assay.

\section{Statistical analysis}

The statistical analysis was generated using SAS Software, version 9.4. Continuous variables are presented as mean and standard deviation, and categorical variables as number and percentage. Values of continuous variables were compared among three groups using a general linear model (GLM) with Tukey adjustment for multiple comparisons, and between two groups using $t$ tests; categorical values were compared using the chi-square test. Correlations $(r)$ were calculated by Pearson correlation. Logistic regression was used for receiver operating characteristic (ROC) curve analysis. Two-sided $p$ values less than 0.05 were considered statistically significant.

\section{Results}

\section{Patient characteristics}

Plasma samples of 116 consecutively enrolled subjects were collected and analyzed for levels of STREM-1. The study population consisted of 33 patients with PAPS (mean age 47.8 years, range $19-88 ; 77.7 \%$ women), 10 asymptomatic persistent positive APLA carriers (mean age 50.6 years, range $28-75 ; 90 \%$ women), and 73 healthy control subjects ( 42.65 years, range $18-67 ; 54.8 \%$ women). The demographic, clinical, and laboratory features of the three groups are shown in Table 1 . Within the PAPS group, 26 patients $(78.78 \%)$ had previous thrombotic $(n=19)$ or obstetric $(n=7)$ events (past PAPS). Seven patients (21.21\%) were evaluated for plasma sTREM-1 level at the time of an acute thrombotic event (current thrombotic PAPS). The prevalence rates of the various types of past thrombotic events in the thrombotic PAPS group $(n=26)$ were as follows: 18 patients $(69.2 \%)$ had an arterial thrombotic event, 4 patients (15.4\%) had a venous thromboembolic event, and 4 patients (15.4\%) had arterial and venous thromboembolic events.

\section{Plasma sTREM-1 levels in patients with PAPS}

Analysis of plasma sTREM-1 levels by group yielded a significantly higher level in the patients with PAPS
$(299.2 \pm 146.7 \mathrm{pg} / \mathrm{ml})$ compared with the healthy control group $(230.2 \pm 85.5 \mathrm{pg} / \mathrm{ml}, p=0.006)$, in the patients with thrombotic PAPS-ever $(327.2 \pm 151.3 \mathrm{pg} / \mathrm{ml})$ compared with the control group ( $p=0.0003$, Fig. 1), in the patients with thrombotic PAPS compared with the patients with obstetric PAPS-past event $(195.1 \pm 58.5 \mathrm{pg} / \mathrm{ml}, p=0.01)$, and in the patients with thrombotic PAPS compared with the asymptomatic APLA carriers $(215.8 \pm 51.6 \mathrm{pg} / \mathrm{ml}, p=0.02$, Fig. 2).

The plasma sTREM-1 level was positively correlated with antinuclear antibody titer $(r=0.33, p=0.03)$. However, there were no statistically significant differences between patients with single, double, or triple APLA positivity (PAPS and asymptomatic groups). Specific values were as follows: single-positive $(n=11)$, mean $290.2 \pm 113.5 \mathrm{pg} / \mathrm{ml}$, median $283.3 \mathrm{pg} / \mathrm{ml}$; double-positive $(n=13)$, mean $267.01 \pm 92.6 \mathrm{pg} / \mathrm{ml}$, median $253.7 \mathrm{pg} / \mathrm{ml}$; triple-positive $(n=19)$, mean $282.5 \pm 171.7 \mathrm{pg} / \mathrm{ml}$, median $247.06 \mathrm{pg} / \mathrm{ml}$. Plasma sTREM-1 levels were not significantly correlated with aCL or anti- $\beta_{2}$ GPI antibody titers.

\section{Relationship of plasma STREM-1 levels to clinical features} Within the PAPS group, higher plasma sTREM-1 levels were positively associated with current thrombotic events $(429.5 \pm 227.5 \mathrm{pg} / \mathrm{ml})$ compared with past thrombotic events $(289.5 \pm 94.65 \mathrm{pg} / \mathrm{ml}, p=0.01)$ (Fig. 3 ) as well as to past obstetric events $(195.1 \pm 58.5 \mathrm{pg} / \mathrm{ml}, p=0.0001)$. The association remained significant on comparison of the patients with thrombotic PAPS-ever with the asymptomatic APLA carrier group $(215.8 \pm 51.6 \mathrm{pg} / \mathrm{ml}, p=0.0002)$ and the healthy controls $(230.2 \pm 85.5 \mathrm{pg} / \mathrm{ml}, p<0.0001)$. In the patients with obstetric PAPS, there was a positive correlation of plasma sTREM-1 level with number of past pregnancies and fetal loss, but it did not reach statistical significance $(r=0.2, p=0.06)$.

The plasma sTREM-1 level was significantly higher compared with controls in the patients with stroke-ever (307.2 $\pm 105.6 \mathrm{pg} / \mathrm{ml}, p=0.03$ ), myocardial infarction-ever (371.6 $\pm 250.04 \mathrm{pg} / \mathrm{ml}, p=0.009$ ), and venous thromboembolic event-ever $(366.67 \pm 203.79 \mathrm{pg} / \mathrm{ml}, p=0.0012)$ (Table 2). Among the patients with PAPS, the plasma sTREM-1 level was significantly higher in those who had stroke-ever than in those who had not $(307.2 \pm 105.6 \mathrm{pg} / \mathrm{ml}$ vs. $240.5 \pm$ $107.2 \mathrm{pg} / \mathrm{ml}, p=0.007)$, and in those who had a venous thromboembolic event than in those who had not (366.7 \pm $203.8 \mathrm{pg} / \mathrm{ml}$ vs. $239.8 \pm 94.2 \mathrm{pg} / \mathrm{ml}, p=0.02)$. There were no significant findings for myocardial infarction.

To test whether plasma sTREM-1 level was associated with inflammatory activity in the patients with PAPS, we performed a correlational analysis of plasma sTREM-1 level with ESR and serum hsCRP levels, platelet count, and serum ferritin level, all of which are clinical biomarkers of the inflammatory acute phase response. We found a significant positive correlation for plasma 
Table 1 Demographics, clinical characteristics, and laboratory profiles of patients with PAPS and asymptomatic APLA

\begin{tabular}{|c|c|c|c|c|}
\hline Parameter & $\begin{array}{l}\text { PAPS } \\
n=33\end{array}$ & $\begin{array}{l}\text { Asymptomatic APLA } \\
n=10\end{array}$ & $\begin{array}{l}\text { Control } \\
n=73\end{array}$ & $P$ value \\
\hline Female & $24(72.7 \%)$ & $9(90 \%)$ & $40(54 \%)$ & 0.012 \\
\hline Age (years), mean (range) & $47.8(19-88)$ & $50.6(28-75)$ & $42.65(18-67)$ & NS \\
\hline Venous thromboembolism & $8(24.24 \%)$ & 0 & 0 & - \\
\hline Arterial thrombosis & $18(54.54 \%)$ & 0 & 0 & - \\
\hline Recurrent fetal loss & $5(15.15 \%)$ & 0 & 0 & - \\
\hline PET & $4(12.12 \%)$ & 0 & 0 & - \\
\hline Intrauterine growth restriction & $4(12.12 \%)$ & 0 & 0 & - \\
\hline Myocardial infarction & $8(24.24 \%)$ & 0 & 0 & - \\
\hline Stroke & $14(42.42 \%)$ & 0 & 0 & - \\
\hline Hypertension & $11(33.33 \%)$ & $1(10 \%)$ & 0 & $<0.001$ \\
\hline Diabetes mellitus & $3(9.09 \%)$ & 0 & 0 & 0.03 \\
\hline Dyslipidemia & $11(33.33 \%)$ & $2(20 \%)$ & 0 & $<0.001$ \\
\hline ANA (mean) & 1:160 & 1:160 & NA & NS \\
\hline $\mathrm{ACL} \operatorname{lgG}(\mathrm{GPL}-\mathrm{U} / \mathrm{ml})$ & $65.35 \pm 65.36$ & $42.68 \pm 67.75$ & NA & NS \\
\hline ACL IgM (MPL-U/ml) & $36.1 \pm 26.51$ & $36.28 \pm 58.59$ & NA & NS \\
\hline$\beta_{2} \mathrm{GPI} \lg \mathrm{G}(\mathrm{U} / \mathrm{ml})$ & $58.82 \pm 67.3$ & $34.34 \pm 59.24$ & NA & NS \\
\hline$\beta_{2} \mathrm{GPI} \operatorname{lgM}(\mathrm{U} / \mathrm{ml})$ & $69.3 \pm 54.42$ & $54.24 \pm 68.66$ & NA & NS \\
\hline LAC dRWT ratio & $1.59 \pm 1.3$ & $1.93 \pm 1.08$ & NA & NS \\
\hline LAC SCT ratio & $1.98 \pm 1.54$ & $1.77 \pm 1.34$ & NA & NS \\
\hline Single-APLA positivity (\%) & $21.21 \%$ & $40 \%$ & - & NS \\
\hline Double-APLA positivity (\%) & $39.39 \%$ & $0 \%$ & - & NS \\
\hline Triple-APLA positivity (\%) & $39.39 \%$ & $60 \%$ & - & NS \\
\hline eGFR $\left(\mathrm{ml} / \mathrm{min} / 1.73 \mathrm{~m}^{2}\right)$ & $89.9 \pm 26.4$ & $88.99 \pm 28.7$ & $97.6 \pm 48.6$ & 0.04 \\
\hline hsCRP (mg/dl) & $0.799 \pm 1.27$ & $0.1871 \pm 0.22$ & NA & 0.02 \\
\hline $\operatorname{ESR}(\mathrm{mm} / \mathrm{h})$ & $28 \pm 19.6$ & $24 \pm 14.22$ & NA & 0.009 \\
\hline Ferritin (mg/dl) & $51.2 \pm 40.75$ & $40.65 \pm 23.75$ & NA & 0.004 \\
\hline Platelets $(K / \mu l)$ & $246 \pm 75.41$ & $243 \pm 58.97$ & NA & NS \\
\hline
\end{tabular}

Values are presented as mean \pm SD or $n(\%)$, unless otherwise stated

$A C L$ anticardiolipin antibody (cutoff values for lgG $18 \mathrm{GPL} \mathrm{U/ml,} \operatorname{lgM} 12 \mathrm{MPL} \mathrm{U} / \mathrm{ml}$ ), ANA antinuclear antibody (assayed by immunofluorescence, positive $\geq 1: 80$ ), APLA antiphospholipid antibodies, $\beta_{2} \mathrm{GPI}$ anti- $\beta_{2}$ glycoprotein antibody (cut-off value for lgG $20 \mathrm{GPL} \mathrm{U/ml,} \mathrm{IgM} 20 \mathrm{MPL} \mathrm{U} / \mathrm{ml}$ ), $d R V V T$ dilute Russell viper venom time test (negative < 1.4), eGFR estimated glomerular filtration rate, ESR erythrocyte sedimentation rate, $h s C R P$ high-sensitive C-reactive protein (normal < 0.5 mg/dl), LAC positive lupus anticoagulant, NA not assayed, NS not significant, PAPS primary antiphospholipid syndrome, PET preeclampsia/toxemia of pregnancy, SCT silica clotting time test (negative $<1.3$ )

* $P$ values for categorical variables were calculated with a Chi-square test, for continuous variables using a general linear model with Tukey adjustment between multiple comparisons and $t$ test between two groups

sTREM-1 level with higher ESR $(r=0.4, p=0.009)$ and higher hsCRP level $(r=0.4, p=0.02)$ (Fig. 4).

No significant positive relationship was found between plasma sTREM-1 level and the presence of comorbidities (hypertension, diabetes mellitus, dyslipidemia, or history of a malignant disorder) or current use of anticoagulants (warfarin or new oral anticoagulants), or low-dose aspirin, hydroxychloroquine, prednisone, or statins.

The plasma sTREM-1 level was significantly associated with current age in the healthy control group $(r=0.63$, $p<0.0001$ ) but not in the PAPS or asymptomatic APLA carrier groups. Since renal function based on GFR physiologically decreases with age [18], we assumed that the age-related increase in plasma sTREM-1 level in the healthy subjects was associated with decreased renal clearance of sTREM-1. Indeed, we found a negative association for plasma sTREM-1 level and eGFR $(r=-0.2$, $p=0.06$ ), but it was statistically significant only in the control group $(r=-0.6, p<0.0001)$. Thus, the correlation observed between plasma sTREM-1 and renal function in the control group is unrelated to levels in the patients with PAPS.

A ROC analysis was performed to evaluate the value of plasma sTREM-1 in discriminating patients with current thrombosis from other patients with PAPS and from asymptomatic APLA carriers and healthy controls. 


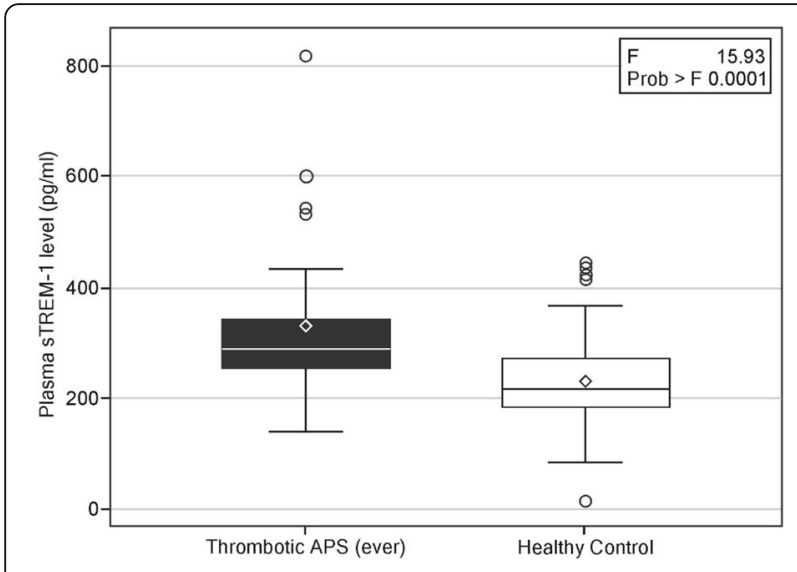

Fig. 1 Levels of plasma soluble triggering receptor expressed on myeloid cells-1 (sTREM-1) in patients with thrombotic primary antiphospholipid syndrome (PAPS)-ever (current and past thrombotic event) ( $n=26)$ compared with healthy controls $(n=73)$ $(p=0.0003)$. Data are shown as box plots. Each box represents the 25th to 75 th percentiles. Lines inside the boxes represent the median. Whiskers indicate the observations directly above the lower fence or below the lower fence, where the fence is defined as $1.5 \times$ interquartile range

The results showed that a cutoff plasma sTREM-1 level of $281 \mathrm{pg} / \mathrm{ml}$ had a sensitivity of $65.4 \%$ and specificity of $100 \%$ for thrombotic events-ever in the PAPS group. A cutoff of $284 \mathrm{pg} / \mathrm{ml}$ had a sensitivity of $57.1 \%$ and specificity of $100 \%$ for current thrombotic PAPS. In the subgroup of thrombotic PAPS-ever, the area under the

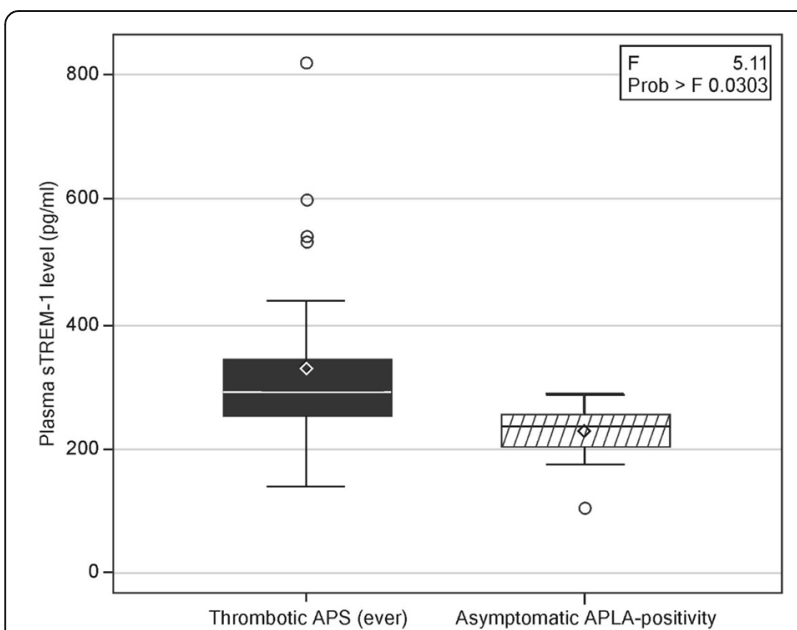

Fig. 2 Levels of plasma soluble triggering receptor expressed on myeloid cells-1 (sTREM-1) in patients with thrombotic primary antiphospholipid syndrome (PAPS)-ever (current and past thrombotic event) $(n=26)$ compared with asymptomatic antiphospholipid antibody (APLA) carriers $(n=10)(p=0.02)$. Data are shown as box plots. Each box represents the 25th to 75th percentiles. Lines inside the boxes represent the median. Whiskers indicate the observations directly above the lower fence, or below the lower fence, where the fence is defined as $1.5 \times$ interquartile range

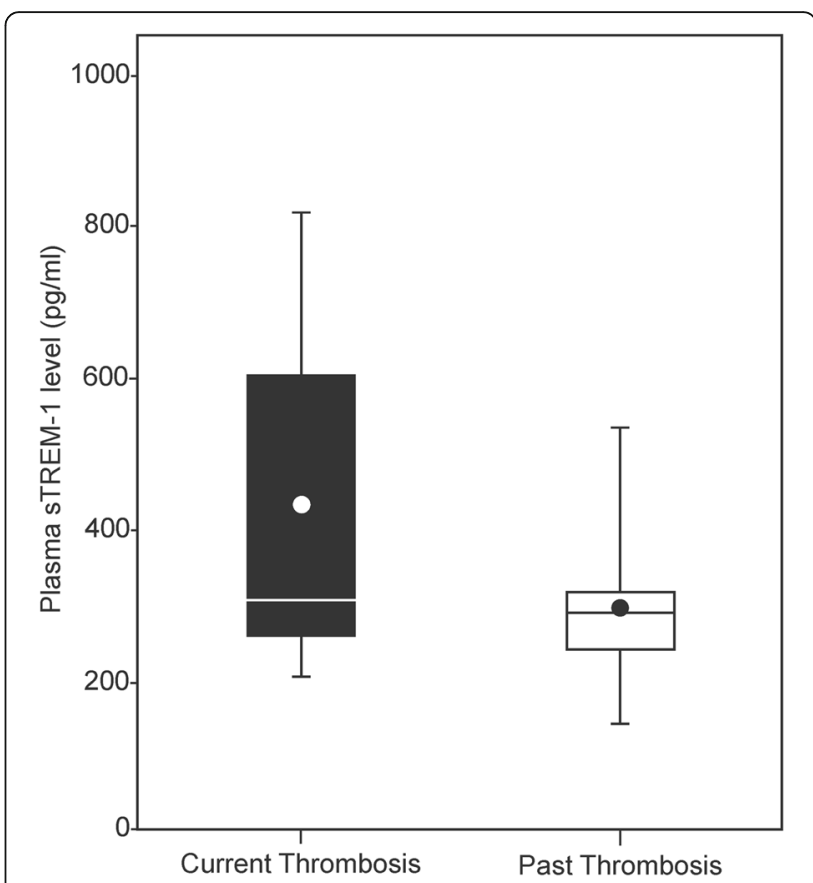

Fig. 3 Plasma soluble triggering receptor expressed on myeloid cells-1 (sTREM-1) level in patients with thrombotic PAPS $(n=26)$ : comparison of current ( $n=19)$ vs. past thrombotic evet $(n=7)(p=0.01)$

curve (AUC) was 0.73 for plasma sTREM-1 (95\% confidence interval (CI) 1.003-1.013, $p=0.0014$; Fig. 5). No significance was found for ESR or serum ferritin level. In the subgroup of current thrombotic PAPS $(n=7)$, the AUC for plasma sTREM-1 was 0.88 (95\% CI 0.686-0.977, $p<0.0001$; Fig. 6), similar to that for the inflammatory biomarkers serum hsCRP $(\mathrm{AUC}=0.96,95 \%$ CI $0.788-0.999, p<0.0001)$ and serum ferritin (AUC $=0.801,95 \%$ CI 0.571-0.941, $p=0.004$ ).

\section{Discussion}

In this case-control study, we found significantly elevated levels of plasma sTREM-1 in patients with current thrombotic PAPS compared with past thrombotic PAPS patients as well as compared with asymptomatic persistent positive APLA carriers and healthy controls (Table 2, Figs. 1, 2, and 3). Plasma sTREM-1 levels positively correlated with thrombotic events in patients with PAPS (Table 2) as well as with high levels of the inflammatory biomarkers ESR $(r=0.4, p=0.009)$ and hsCRP $(r=0.4$, $p=0.02$, Fig. 4 ), suggesting that it is associated with a low-grade inflammatory state. Interestingly, neither APLA titers nor the presence of single, double, or triple positivity was correlated with levels of plasma sTREM-1 in our cohort.

Although persistently positive triple-positive APLA is a strong risk factor for thrombosis in APS [19], the presence of APLA is by itself not sufficient to trigger clot formation [3]. Previous findings in patients with APS of 
Table 2 Plasma levels of sTREM-1 by clinical manifestations of PAPS $(n=33)$ compared with controls $(n=73)$

\begin{tabular}{lllll}
\hline Clinical manifestation of PAPS $(n)$ & Mean \pm SD $(\mathrm{pg} / \mathrm{ml})$ & Median $(\mathrm{pg} / \mathrm{ml})$ & Range $(\mathrm{pg} / \mathrm{ml}) \quad$ value* \\
\hline Past thrombosis (19) & $289.5 \pm 94.65$ & 287.5 & $138.04-532.7$ & $203.3-817.6$ \\
Current thrombosis (7) & $429.6 \pm 227.5$ & 303.3 & $90.4-284.2$ & $\mathrm{NS}$ \\
Past obstetric event (7) & $195.1 \pm 58.5$ & 198.3 & $203.3-601.4$ \\
Current arterial thrombosis (5) & $377.2 \pm 180.41$ & 283.3 & $141.98-817.62$ & $\mathbf{N}$ \\
Venous thromboembolism-ever (9) & $366.67 \pm 203.79$ & 316.82 & $238.42-817.62$ & 0.001 \\
Ml-ever (5) & $371.6 \pm 250.04$ & 257.7 & $170.02-540.29$ & 0.003 \\
Stroke-ever (14) & $307.2 \pm 105.6$ & 287.9 & 0.03 \\
\hline
\end{tabular}

MI myocardial infarction, NS not statistically significant, PAPS primary antiphospholipid syndrome, sTREM-1 soluble receptor expressed on myeloid cells-1 ${ }^{*}$ Analysis of differences in mean plasma sTREM-1 level between patients with various clinical manifestations of PAPS and healthy controls; mean sTREM-1 of the healthy control group, $230.18 \pm 85.52 \mathrm{pg} / \mathrm{ml}$

elevated levels of inflammatory markers, including CRP and serum amyloid-A [20-25] relative to controls, as well as activated monocytes [26] and increased production of proinflammatory cytokines relative to controls [27, 28], suggest that PAPS is associated with a low-grade inflammatory state and an innate immune response. Inflammation involving the activation of endothelial cells, monocytes, and platelets has been shown to play a role in clot formation in animal models of APS [29-31]. Anti- $\beta_{2}$ GPI antibodies can trigger endothelial cell surface molecules such as annexin A2 (bound by

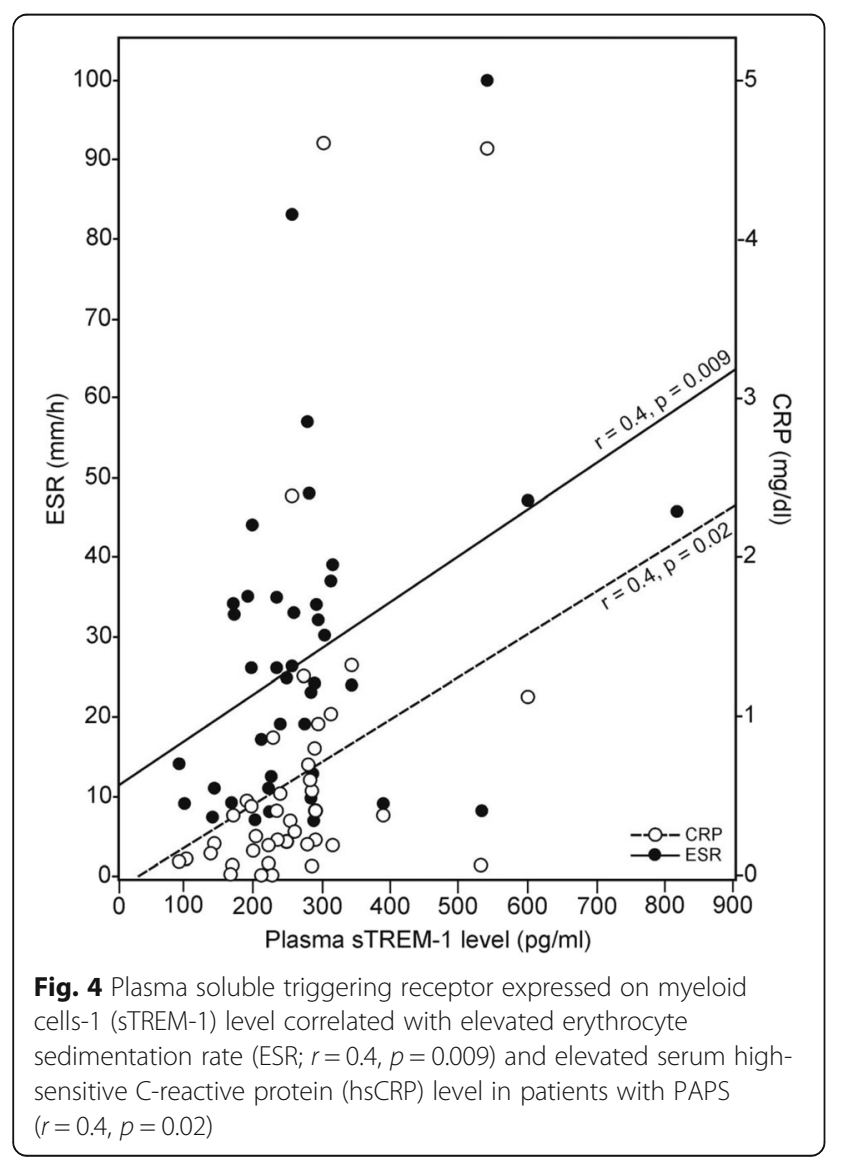

$\beta_{2}$ GPI) and TLR-4 [32] and induce monocytes to increase tissue factor expression and release tumor necrosis factor $\alpha$ [33].

An experimental study of arterial thrombosis comparing wild-type with TLR-4-deficient mice treated with APLA [34] showed that TLR-4 modulates APLA-mediated prothrombotic effects by increasing monocyte production of tissue factor [34]. Moreover, mice treated with APLA together with a TLR-4 agonist (LPS) expressed higher levels of tissue factor activity in plasma and leukocytes [34]. Similarly, another in-vivo study found that clot size was smaller in LPS-nonresponsive mice $\left(\mathrm{LPS}^{-/-}\right)$than in LPS-responsive mice [7]. Accordingly, human anti- $\beta_{2}$ GPI antibodies derived from patients with thrombotic APS showed upregulated tissue factor expression in a TLR-4-,

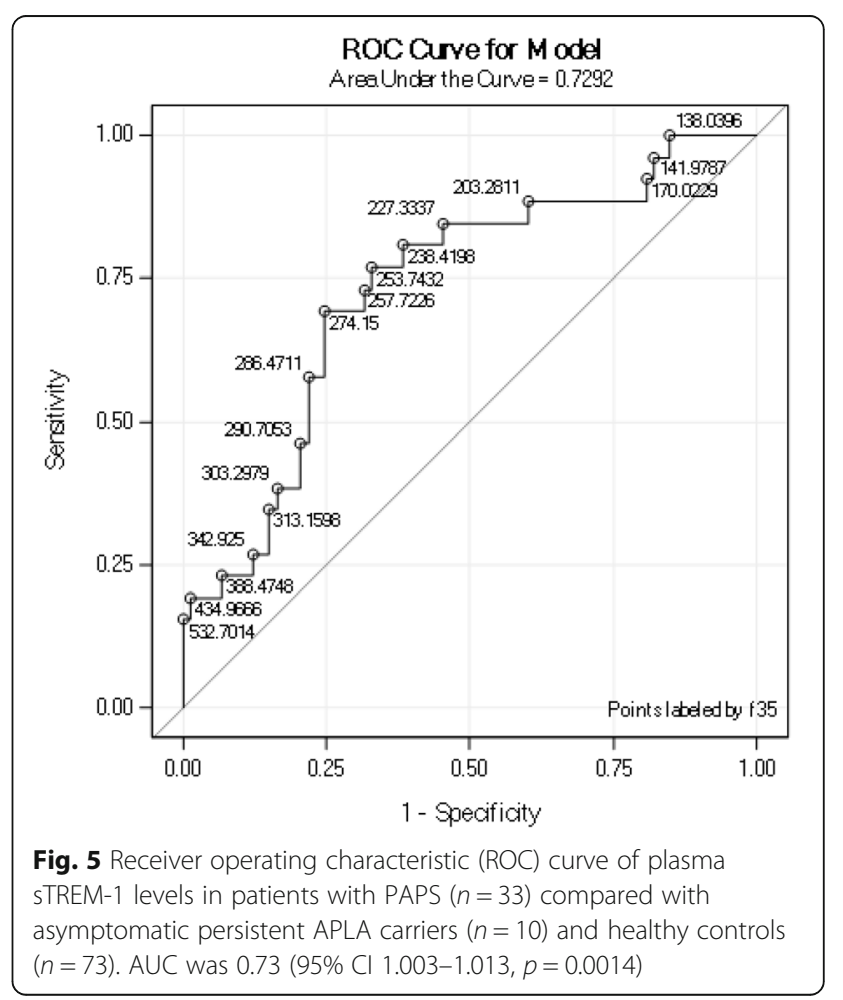




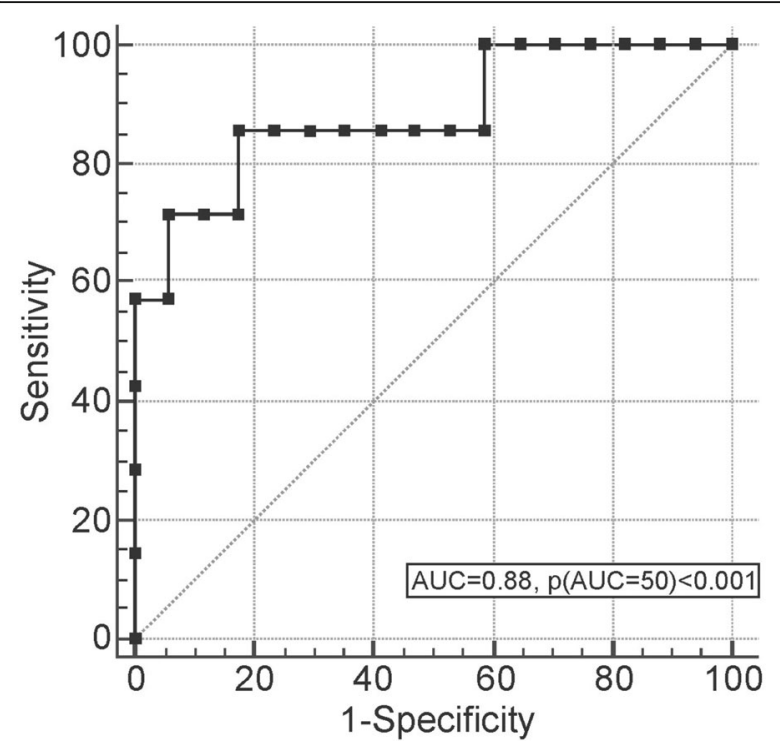

Fig. 6 Receiver operating characteristic curve of plasma sTREM-1 levels in patients with current thrombotic PAPS $(n=7)$ compared with asymptomatic persistent APLA carriers $(n=10)$ and healthy controls $(n=73)$. Area under the curve (AUC) was $0.88(95 \% \mathrm{Cl}$ $0.686-0.977, p<0.0001)$

p38 MAP kinase-, and NF-kappaB-dependent pathway [35]. These findings are in line with the two-hit hypothesis of APS-associated thrombosis which suggests that a "first hit" injury disrupts the endothelium and a "second hit" potentiates thrombus formation [3].

TREM-1 is a newly identified member of the immunoglobulin superfamily of receptors expressed in TLR-4mediated activated macrophages and neutrophils. Activation of the innate immune system in response to such triggers as LPS-mediated TLR-4 activation leads to degranulation, respiratory burst, release of proinflammatory cytokines, and phagocytosis [36]. During bacterial invasion, the TLR-4-induced inflammatory response is amplified [9-12, 37] by the integration of TLR- 4 with activated membrane TREM-1 [38]. Studies in humans have shown that upregulation of monocyte- and neutrophilmembrane TREM-1 during endotoxemia is associated with an increased release of sTREM-1 in blood and other biological fluids $[13,39]$. This process also occurs in various noninfectious, chronic inflammatory disorders [40], including rheumatoid arthritis $[41,42]$ and systemic lupus erythematosus [17, 43]. Thus, the plasma level of STREM-1 may serve as a reliable biomarker for TLR-4mediated innate immune activation in infectious as well as sterile inflammatory disorders, including autoimmune diseases.

The results of our study suggest that thrombotic PAPS is characterized by an innate immune activation state, in accordance with earlier reports of activated monocytes in patients with APS [26-28]. Indeed, APLA-induced activation of the TLR-4-dependent signaling pathway in endothelial cells [4] and monocytes [34, 44], as well as neutrophils [45], has been demonstrated in APS. A TLR-4-mediated innate immune activation along with TREM-1 upregulation is supported by the correlation found in our study between elevated plasma levels of sTREM-1 and a low-grade inflammatory state in the patients with current or past thrombotic events. Thus, TREM-1 upregulation might be involved in the TLR-4-mediated mechanism of clot formation in APS. Another potential role for TREM-1 in thrombotic APS was suggested by recent data showing that TREM- 1 is constitutively expressed in platelet $\alpha$-granules and which, upon platelet activation, is mobilized to the platelet surface [46]. Pharmacologic inhibition of TREM-1 in platelets from humans and also from trem-1 ${ }^{-1-}$ mice reduced both the platelet activation as well as the platelet aggregation induced by collagen, adenosine diphosphate, and thrombin [46]. Moreover, in vivo TREM-1 inhibition decreased thrombus formation in a carotid artery model of thrombosis and protected mice during pulmonary embolism. Thus, TREM-1 may participate in platelet aggregation, a pivotal step in clot formation.

Plasma sTREM-1 levels were positively correlated with older age in the healthy control group $(r=0.63, p<0.0001)$ but not in the PAPS and asymptomatic APLA carrier groups. Given the physiological decrease in glomerular filtration rate with aging [18], we assume this finding is attributable to decreased renal clearance of sTREM- 1 . The lack of association of the plasma STREM-1 level with age or eGFR in the patients with PAPS and the asymptomatic APLA carriers suggests that neither age nor renal function has clinical significance with respect to plasma sTREM-1 levels in these patient groups.

Our study has several limitations. The small number of asymptomatic APLA carriers in our cohort and the cross-sectional design of the study preclude any conclusions regarding the power of plasma sTREM-1 levels to predict a thrombotic event in asymptomatic APLA carriers or patients with obstetric PAPS. These issues warrant a prospective, longitudinal study of a larger group of asymptomatic APLA carriers. Further studies are also needed to determine whether plasma sTREM-1 levels can discriminate arterial from venous thrombosis. As we excluded pregnant women with APLA, we could not determine the significance of plasma STREM-1 in predicting the occurrence or severity of obstetrical fetal and maternal morbidity in APS.

\section{Conclusion}

Taken together, our findings of an elevated plasma sTREM-1 level in patients with thrombotic PAPS and its correlation with elevated levels of ESR and serum hsCRP suggest that thrombotic APS is characterized by 
TLR-4-mediated innate immune activation [34-36] and possibly platelet activation [46]. Moreover, the correlation of elevated plasma sTREM-1 with venous and arterial thrombotic events suggests that plasma sTREM-1 can be used as a biomarker of thrombosis during follow-up of patients with PAPS.

\section{Abbreviations}

aCL: Anticardiolipin; APLA: Antiphospholipid antibody; APS: Antiphospholipid syndrome; AUC: Area under the curve; Cl: Confidence interval; eGFR: Estimated glomerular filtration rate; ESR: Erythrocyte sedimentation rate; GPI: Glycoprotein I; hsCRP: High-sensitive C-reactive protein; IUFD: Intrauterine fetal death; LAC: Lupus anticoagulant; LPS: Lipopolysaccharide; PAPS: Primary antiphospholipid syndrome; ROC: Receiver operating characteristic; sTREM-1: Soluble triggering receptor expressed on myeloid cells-1; TLR: Toll-like receptor; TREM-1: Triggering receptor expressed on myeloid cells-1

\section{Acknowledgements}

None.

\section{Availability of data and supporting materials}

The datasets used and/or analyzed during the current study are available from the corresponding author on reasonable request.

\section{Funding}

None.

\section{Authors' contributions}

YE collected clinical data, analyzed and interpreted data, wrote the manuscript, and gave final approval of the version to be published. VK analyzed and interpreted data. EPS collected clinical data. SO collected clinical data. ADL collected clinical data. YPPB collected clinical data. ME collected clinical data. YM conceived and designed the study, collected clinical data, analyzed and interpreted data, wrote the manuscript, and gave final approval of the version to be published. All authors read and approved the final manuscript

\section{Ethics approval and consent to participate}

The study protocol was reviewed and approved by the local Institutional Review Board, and all participants provided written informed consent.

\section{Consent for publication}

Not applicable.

\section{Competing interests}

The authors declare that they have no competing interests.

\section{Publisher's Note}

Springer Nature remains neutral with regard to jurisdictional claims in published maps and institutional affiliations.

\section{Author details}

${ }^{1}$ Rheumatology Unit, Rabin Medical Center - Beilinson Hospital, 4941492 Petach Tikva, Israel. 'Laboratory of Inflammation Research, Felsenstein Medical Research Center, Rabin Medical Center - Beilinson Hospital, Petach Tikva, Israel. ${ }^{3}$ Sackler Faculty of Medicine, Tel Aviv University, Tel Aviv, Israel.

Received: 15 May 2018 Accepted: 27 November 2018

Published online: 07 January 2019

\section{References}

1. Cervera R, Piette JC, Font J, Khamashta MA, Shoenfeld Y, Camps MT, et al. Euro-Phospholipid Project Group. Antiphospholipid syndrome: clinical and immunologic manifestations and patterns of disease expression in a cohort of 1,000 patients. Arthritis Rheum. 2002:46:1019-27.

2. Meroni PL, Borghi MO, Raschi E, Tedesco F. Pathogenesis of the antiphospholipid syndrome (APS): understanding the antibodies. Nat Rev Rheumatol. 2011;7:330-9.
3. Akira S, Uematsu S, Takeuchi O. Pathogen recognition and innate immunity. Cell. 2006:124:783-801.

4. Raschi E, Chighizola CB, Grossi C, Ronda N, Gatti R, Meroni PL, et al. $\beta 2-$ glycoprotein I, lipopolysaccharide and endothelial TLR4: three players in the two hit theory for anti-phospholipid-mediated thrombosis. J Autoimmun. 2014:55:42-50.

5. Xu G, Wen $H$, Zhou H, Guo D, Zhou F, Chen D, et al. Involvement of IRAKs and TRAFs in anti- $\beta_{2}$ GPI/ $\beta_{2}$ GPI-induced tissue factor expression in THP-1 cells. Thromb Haemost. 2011;106:1158-69.

6. Zhou H, Yan Y, Xu G, Zhou B, Wen H, Guo D, et al. Toll-like receptor (TLR)-4 mediates anti-B2GPI/B2GPI-induced tissue factor expression in THP-1 cells. Clin Exp Immunol. 2011;163:189-98.

7. Pierangeli SS, Vega-Ostertag ME, Raschi E, Liu X, Romay-Penabad Z, De Micheli $V$, et al. Toll-like receptor and antiphospholipid mediated thrombosis: in vivo studies. Ann Rheum Dis. 2007:66:1327-33.

8. Benhamou Y, Bellien J, Armengol G, Brakenhielm E, Adriouch S, lacob M, et al. Role of Toll-like receptors 2 and 4 in mediating endothelial dysfunction and arterial remodeling in primary arterial antiphospholipid syndrome. Arthritis Rheumatol. 2014:66:3210-20.

9. Bouchon A, Facchetti F, Weigand MA, Colonna M. TREM-1 amplifies inflammation and is a crucial mediator of septic shock. Nature. 2001:410: 1103-7.

10. Klesney-Tait J, Turnbull IR, Colonna M. The TREM receptor family and signal integration. Nat Immunol. 2006;7:1266-73.

11. Tessarz AS, Cerwenka A. The TREM-1/DAP12 pathway. Immunol Lett. 2008; 116:111-6.

12. Colonna M. TREMs in the immune system and beyond. Nat Rev Immunol. 2003:3:445-53.

13. Gibot S, Kolopp-Sarda MN, Bene MC, Bollaert PE, Lozniewski A, Mory F, et al A soluble form of the triggering receptor expressed on myeloid cells-1 modulates the inflammatory response in murine sepsis. J Exp Med. 2004; 200:1419-26.

14. Miyakis S, Lockshin MD, Atsumi T, Branch DW, Brey RL, Cervera R, et al. International consensus statement on an update of the classification criteria for definite antiphospholipid syndrome (APS). J Thromb Haemost. 2006;4: 295-306.

15. Levey AS, Bosch JP, Lewis JB, Greene T, Rogers N, Roth D. A more accurate method to estimate glomerular filtration rate from serum creatinine: a new prediction equation. Modification of Diet in Renal Disease Study Group. Ann Intern Med. 1999:130:461-70.

16. Pengo V, Tripodi A, Reber G, Rand JH, Ortel TL, Galli M, et al. Subcommittee on Lupus Anticoagulant/Antiphospholipid Antibody of the Scientific and Standardization Committee of the International Society on Thrombosis and Haemostasis. Update of the guidelines for lupus anticoagulant detection. Subcommittee on Lupus Anticoagulant/Antiphospholipid Antibody of the Scientific and Standardization Committee of the International Society on Thrombosis and Haemostasis. J Thromb Haemost. 2009:7:1737-40.

17. Molad Y, Pokroy-Shapira E, Kaptzan T, Monselise A, Shalita-Chesner M, Monselise $Y$. Serum soluble triggering receptor on myeloid cells-1 (sTREM-1) is elevated in systemic lupus erythematosus but does not distinguish between lupus alone and concurrent infection. Inflammation. 2013;36:1519-24.

18. Cohen E, Nardi Y, Krause I, Goldberg E, Milo G, Garty M, et al. A longitudinal assessment of the natural rate of decline in renal function with age. J Nephrol. 2014;27:635-41.

19. Yelnik CM, Urbanski G, Drumez E, Sobanski V, Maillard H, Lanteri A, et al. Persistent triple antiphospholipid antibody positivity as a strong risk factor of first thrombosis, in a long-term follow-up study of patients without history of thrombosis or obstetrical morbidity. Lupus. 2017;26:163-9.

20. Miesbach W, Gökpinar B, Gilzinger A, Claus D, Scharrer I. Predictive role of hs-C-reactive protein in patients with antiphospholipid syndrome. Immunobiology. 2005;210:755-60.

21. Sailer T, Vormittag R, Pabinger I, Vukovich T, Lehr S, Quehenberger $P$, et al. Inflammation in patients with lupus anticoagulant and implications for thrombosis. J Rheumatol. 2005;32:462-8.

22. Ames PR, Tommasino C, Brancaccio V, Ciampa A. C-reactive protein in primary antiphospholipid syndrome. J Rheumatol. 2007;34:650.

23. Sidelmann JJ, Sjøland JA, Gram J, Bertelsen V, Mourits-Andersen T, Münster $\mathrm{H}$, et al. Lupus anticoagulant is significantly associated with inflammatory reactions in patients with suspected deep vein thrombosis. Scand J Clin Lab Invest. 2007;67:270-9. 
24. Bećarević M, Majkić-Singh N. High-sensitivity C-reactive protein: discriminator between patients with primary and secondary antiphospholipid syndrome. Clin Biochem. 2008;41:1449-53.

25. Ames PR, Antinolfi I, Ciampa A, Batuca J, Scenna G, Lopez LR, et al. Primary antiphospholipid syndrome: a low-grade auto-inflammatory disease? Rheumatology (Oxford). 2008;47:1832-7.

26. López-Pedrera C, Buendía P, Cuadrado MJ, Siendones E, Aguirre MA Barbarroja N, et al. Antiphospholipid antibodies from patients with the antiphospholipid syndrome induce monocyte tissue factor expression through the simultaneous activation of NF-kappaB/Rel proteins via the p38 mitogen-activated protein kinase pathway, and of the MEK-1/ERK pathway. Arthritis Rheum. 2006;54:301-11.

27. Bernales I, Fullaondo A, Marín-Vidalled MJ, Ucar E, Martínez-Taboada V, López-Hoyos M, et al. Innate immune response gene expression profiles characterize primary antiphospholipid syndrome. Genes Immun. 2008;9: 38-46.

28. Martirosyan A, Petrek M, Navratilova Z, Blbulyan A, Boyajyan A, Manukyan G. Differential regulation of proinflammatory mediators following LPS- and ATP-induced activation of monocytes from patients with antiphospholipid syndrome. Biomed Res Int. 2015;2015:292851.

29. de Groot PG, de Laat B. Mechanisms of thrombosis in systemic lupus erythematosus and antiphospholipid syndrome. Best Pract Res Clin Rheumatol. 2017;31:334-41.

30. Giannakopoulos B, Krilis SA. The pathogenesis of the antiphospholipid syndrome. N Engl J Med. 2013;368:1033-44.

31. Mehdi AA, Uthman I, Khamashta M. Antiphospholipid syndrome: pathogenesis and a window of treatment opportunities in the future. Eur J Clin Investig. 2010;40:451-64.

32. Ma K, Simantov R, Zhang JC, Silverstein R, Hajjar KA, McCrae KR. High affinity binding of beta 2-glycoprotein I to human endothelial cells is mediated by annexin II. J Biol Chem. 2000;275:15541-8.

33. Sorice M, Longo A, Capozzi A, Garofalo T, Misasi R, Alessandri C, et al. Antibeta2-glycoprotein I antibodies induce monocyte release of tumor necrosis factor alpha and tissue factor by signal transduction pathways involving lipid rafts. Arthritis Rheum. 2007;56:2687-97.

34. Laplante P, Fuentes R, Salem D, Subang R, Gillis MA, Hachem A, et al. Antiphospholipid antibody-mediated effects in an arterial model of thrombosis are dependent on Toll-like receptor 4. Lupus. 2016;25:162-76.

35. Lambrianides A, Carroll CJ, Pierangeli SS, Pericleous C, Branch W, Rice J, et al. Effects of polyclonal lgG derived from patients with different clinical types of the antiphospholipid syndrome on monocyte signaling pathways. J Immunol. 2010;184:6622-8.

36. Nathan C, Ding A. TREM-1: a new regulator of innate immunity in sepsis syndrome. Nat Med. 2001;7:530-2.

37. Pelham CJ, Agrawal DK. Emerging roles for triggering receptor expressed on myeloid cells receptor family signalling in inflammatory diseases. Expert Rev Clin Immunol. 2014;10:243-56.

38. Arts RJ, Joosten LA, van der Meer JW, Netea MG. TREM-1: intracellular signalling pathways and interaction with pattern recognition receptors. J Leukoc Biol. 2013;93:209-15.

39. Knapp S, Gibot S, de Vos A, Versteeg HH, Colonna M, van der Poll T. Cutting edge: expression patterns of surface and soluble triggering receptor expressed on myeloid cells-1 in human endotoxemia. J Immunol. 2004;173: $7131-4$

40. Pelham CJ, Pandya AN, Agrawal DK. Triggering receptor expressed on myeloid cells receptor family modulators: a patent review. Expert Opin Ther Pat. 2014;24:1383-95.

41. Collins CE, La DT, Yang HT, Massin F, Gibot S, Faure G, et al. Elevated synovial expression of triggering receptor expressed on myeloid cells 1 in patients with septic arthritis or rheumatoid arthritis. Ann Rheum Dis. 2009; 68:1768-74.

42. Molad Y, Ofer-Shiber S, Pokroy-Shapira E, Oren S, Shay-Aharoni H, Babai I. Soluble triggering receptor expressed on myeloid cells-1 is a biomarker of anti-CCP-positive, early rheumatoid arthritis. Eur J Clin Investig. 2015;45:557-64.

43. Bassyouni IH, Fawzi S, Gheita TA, Bassyouni RH, Nasr AS, El Bakry SA, et al. Clinical association of a soluble triggering receptor expressed on myeloid cells-1 (sTREM-1) in patients with systemic lupus erythematosus. Immunol Investig. 2017;46:38-47.
44. Agar C, de Groot PG, Mörgelin M, Monk SD, van Os G, Levels JH, et al. $\beta_{2^{-}}$ glycoprotein I: a novel component of innate immunity. Blood. 2011;117: 6939-47.

45. Gladigau G, Haselmayer P, Scharrer I, Munder M, Prinz N, Lackner K, et al. A role for Toll-like receptor mediated signals in neutrophils in the pathogenesis of the anti-phospholipid syndrome. PLoS One. 2012;7:e42176.

46. Jolly L, Lemarie J, Carrasco K, Popovic B, Derive M, Boufenzer A, et al. Triggering receptor expressed on myeloid cells-1: a new player in platelet aggregation. Thromb Haemost. 2017;117:1772-81.

\section{Ready to submit your research? Choose BMC and benefit from:}

- fast, convenient online submission

- thorough peer review by experienced researchers in your field

- rapid publication on acceptance

- support for research data, including large and complex data types

- gold Open Access which fosters wider collaboration and increased citations

- maximum visibility for your research: over $100 \mathrm{M}$ website views per year

At BMC, research is always in progress.

Learn more biomedcentral.com/submissions 